\title{
How much yield loss has been caused by extreme temperature stress to the irrigated rice production in China?
}

\author{
Pin Wang ${ }^{1} \cdot$ Zhao Zhang $^{1} \cdot$ Yi Chen ${ }^{1} \cdot$ Xing Wei $^{1} \cdot$ \\ Boyan Feng ${ }^{1} \cdot$ Fulu Tao $^{2}$
}

Received: 2 June 2015 / Accepted: 22 October 2015 /Published online: 2 November 2015

(C) Springer Science+Business Media Dordrecht 2015

\begin{abstract}
Extreme temperature stress (ETS) is recognized as an important threat to the food supply in China. However, how much yield loss caused by ETS ( $\mathrm{YL}_{\mathrm{ETS}}$ ) to the irrigated rice production still remains unclear. In this study, we provided a prototype for $\mathrm{YL}_{\mathrm{ETS}}$ assessments by using a process-based crop model (MCWLA-Rice) with the ETS impacts explicitly parameterized, to help understand the spatio-temporal patterns of $\mathrm{YL}_{\mathrm{ETS}}$ and the mechanism underlying the ETS impacts at a $0.5^{\circ} \times 0.5^{\circ}$ grid scale in the major irrigated rice planting areas across China during 1981-2010. On the basis of the optimal 30 sets of parameters, the ensemble simulations indicated the following: Regions I (northeastern China) and $\mathrm{III}_{2}$ (the mid-lower reaches of the Yangtze River) were considered to be the most vulnerable areas to ETS, with the medium $\mathrm{YL}_{\mathrm{ETS}}$ of 18.4 and $12.9 \%$, respectively. Furthermore, large $\mathrm{YL}_{\mathrm{ETS}}$ values ( $>10 \%$ ) were found in some portions of Region II (the Yunnan-Guizhou Plateau), western Region III $_{1}$ (the Sichuan Basin), the middle of Region IV_ER (southern China cultivated by early rice), and the west and southeast of Region IV_LR (southern China cultivated by late rice). Over the past several decades, a significant decrease in $\mathrm{YL}_{\mathrm{ETS}}$ was detected in most of Region I and in northern Region IV_LR (with the medians of -0.53 and $-0.28 \%$ year $^{-1}$, respectively). However, a significant increase was found in most of Region III (including $\mathrm{III}_{1}$ and $\mathrm{III}_{2}$ ) and in Region IV_ER, particularly in the last decade (2001-2010). Overall, reduced cold stress has improved the conditions for irrigated rice production across
\end{abstract}

Electronic supplementary material The online version of this article (doi:10.1007/s10584-015-1545-5) contains supplementary material, which is available to authorized users.

\section{Zhao Zhang}

zhangzhao@bnu.edu.cn

1 State Key Laboratory of Earth Surface Processes and Resources Ecology/Key Laboratory of Environmental Change and Natural Disaster, MOE/Academy of Disaster Reduction and Emergency Management, Beijing Normal University, Beijing 100875, China

2 Institute of Geographical Sciences and Natural Resources Research, Chinese Academy of Sciences, Beijing 100101, China 
large parts of China. Nevertheless, to improve the accuracy of $\mathrm{YL}_{\mathrm{ETS}}$ estimations, more accurate yield loss functions and multimodel ensembles should be developed.

\section{Introduction}

Rice (Oryza sativa L.) is a staple food for more than half of the world's population (Seck et al. 2012). However, extreme temperatures are destructive to rice growth and hence critical to rice productivity (Rezaei et al. 2015; Teixeira et al. 2013). In particular, as the world's largest rice producer, China has witnessed significant climate warming since the 1980s (Lobell et al. 2011a; Tao et al. 2012), coming with increased frequency and severity of extreme temperature events across the major irrigated rice planting areas (Tao et al. 2013). Recently, numerous studies have found rice production in China is severely threatened by extreme temperature stress (ETS) in different meteorological index calculations; however, these studies have seldom evaluated the associations between the ETS indexes and yield loss (Sun and Huang 2011; Zhang et al. 2014). Therefore, it is necessary to take a deeper look at the extent and mechanisms of yield loss caused by ETS $\left(\mathrm{YL}_{\mathrm{ETS}}\right)$ in the irrigated rice cultivation area of China.

In general, the lack of studies connecting yield loss with ETS has largely been attributed to a lack of historical $\mathrm{YL}_{\mathrm{ETS}}$ datasets over large areas. During rice growing season, farmers and agronomists could hardly capture the damage caused by extreme temperature events because ETS mainly affects rice biophysical processes rather than plant appearances (e.g., leaf color and shape) (Rezaei et al. 2015). Recently, some global studies have turned to statistical models to assess ETS impacts by using the indexes of normal and killing growing-degree-days (Butler and Huybers 2013; Lobell et al. 2011b, 2012). Such efforts have also been made for rice crops in China by Wang et al. (2014a), who did find that past rice yields were sensitive to ETS in a few scattered areas. However, rice yields in some areas that are typically vulnerable to ETS, such as the mid-lower reaches of the Yangtze River (Tao et al. 2013; Zhang et al. 2011), did not show a significant response to the ETS indexes. The potential reason for the weak responses was the deficiency inherent in the statistical methods, such as the difficulty in separating $\mathrm{YL}_{\mathrm{ETS}}$ from the final yield which was impacted by both climatic and anthropogenic factors (e.g., cultivar choices and management practices). As an alternative, a process-based crop model has been recognized as an effective method for $\mathrm{YL}_{\mathrm{ETS}}$ estimation (Ewert et al. 2014; Moriondo et al. 2011). However, an important concern is that $\mathrm{YL}_{\mathrm{ETS}}$ simulations are largely dependent on the processes and mechanisms of a certain applied model, particularly its ETS module (Challinor et al. 2005; Ewert et al. 2014; Iizumi et al. 2009; Tao and Zhang 2013). For rice crops, it has been recognized that extreme temperatures that occur at crucial times (e.g., booting and heading-flowering) would cause a significant increase in the percentage of sterile spikelet, and hence would drastically reduce the final production (Moriondo et al. 2011; Rezaei et al. 2015). However, many crop models have often lacked explicit parameterization of such key impacts on rice productivity (Ewert et al. 2014; Wheeler and von Braun 2013), and might have generated underestimates of $\mathrm{YL}_{\mathrm{ETS}}$ levels.

Therefore, in this study, great effort would be made to assess $\mathrm{YL}_{\mathrm{ETS}}$ over the past decades in China. We selected the Model to capture the Crop-weather relationship over a Large Area (MCWLA)-Rice crop model (Tao and Zhang 2013; Tao et al. 2009) for the following reasons: (a) it combines the benefits of more empirical modeling methods (low input data requirements, validity over large areas) with the benefits of a process-based approach (the potential to capture variability due to different weather conditions); (b) it simulates crop response to climate 
variables and elevated $\mathrm{CO}_{2}$ by adopting photosynthesis-stomatal conductance coupling, instead of using proportionality factors as do many crop models; (c) it explicitly parameterizes the impacts of ETS particularly around the sensitive stage on rice yield, which is expected to improve the reliability of $\mathrm{YL}_{\mathrm{ETS}}$ assessments. Based on the MCWLA-Rice model, we aimed to (i) provide a prototype for $\mathrm{YL}_{\mathrm{ETS}}$ assessments to aid understanding of the spatio-temporal patterns of $\mathrm{YL}_{\mathrm{ETS}}$ in the major irrigated rice planting areas across China; (ii) identify the particular areas severely hit by historical ETS and those suffering from increasing $\mathrm{YL}_{\mathrm{ETS}}$; and (iii) explore the mechanisms underlying ETS impacts in different areas.

\section{Materials and methods}

\subsection{Model description}

The details on the development of the MCWLA-Rice model have been described in Tao et al. (2009) and Tao and Zhang (2013). The brief description about this model is as follows: it is designed to investigate the impacts of weather and climate variability (change) on crop growth, development, and productivity at a large scale; the simulations of rice phenological development, leaf development, and the ETS impacts on the harvest index (see the equations in the Supplementary Materials) are similar to the approach by Horie et al. (1995); soil hydrology is modeled following the semi-empirical approach of Haxeltine and Prentice (1996); it adopts the robust, process-based representation of the coupled $\mathrm{CO}_{2}$ and $\mathrm{H}_{2} \mathrm{O}$ exchanges in the LundPostdam-Jena (LPJ) dynamic global vegetation models (Bondeau et al. 2007; Haxeltine and Prentice 1996); the impacts on yield due to factors other than weather (e.g., pests, disease and management factors) are modeled in a simplified way as GLAM (Challinor et al. 2004); biomass is accumulated from the photosynthate and further transferred into crop yield by harvest index. The planting window is set to allow automatic planting once the soil water content is larger than half of the soil water capacity or planting regardless of the end of the planting window; there is automatically irrigation of $50 \mathrm{~mm}$ when the ratio of daily transpiration and potential transpiration drops below 0.8 (Tao and Zhang 2013). Besides, typical harvest dates from Sun and Huang's study (2011) were used here, to force a complete yearly simulation in the areas suffering severely from delayed cool injury (e.g., northeastern China).

\subsection{Study area and data sources}

In this study, MCWLA-Rice was run on each $0.5 \times 0.5$ grid with a rice cultivation fraction $\geq 0.01$ across 16 major production provinces in China (Fig. 1). Rice cultivation in these areas contributes $\sim 96$ and $\sim 94 \%$ of the total rice area and rice production in China, respectively; single rice dominates northern and southwestern China, while double rice (i.e., early-late rice rotation) is common in south of $30^{\circ} \mathrm{N}$ latitude (Sun and Huang 2011). The study area was divided into four regions in Fig. 1 based on Wang et al. (2014a) and Zhang et al. (2014). The characteristics of the four regions are listed in Table S1 in the Supplementary Materials.

MCWLA-Rice requires daily weather inputs of the maximum and minimum temperatures, precipitation, relative humidity, and fractional sunshine hours. These datasets of $0.5^{\circ} \times$ $0.5^{\circ}$ resolution grids were obtained from the State Key Laboratory of Earth Surface Processes and Resource in China (Yuan et al. 2015). The soil texture and hydrological properties data were based on the Food Agriculture Organization soil dataset (FAO 1991). 


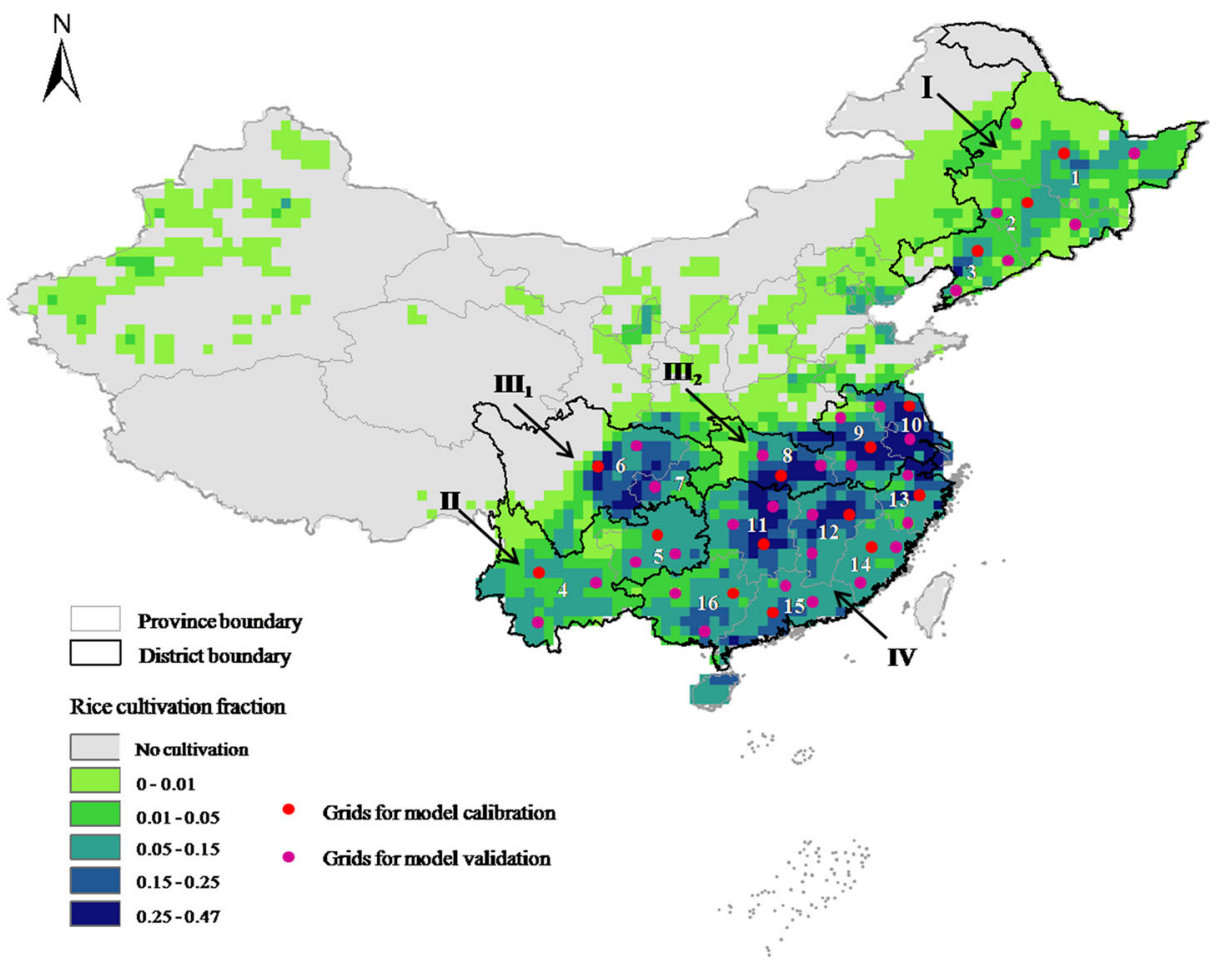

Fig. 1 Rice cultivation zones and the grids for calibration and validation in China. Note: the study area included four regions (16 provinces): $I$, single rice in northeastern China; $I I$, single rice in the Yunnan-Guizhou Plateau; III, single rice in the Sichuan Basin $\left(I I_{1}\right.$, including Sichuan and Chongqing provinces) and the mid-lower reaches of the Yangtze River $\left(\mathrm{II}_{2}\right.$, including Hubei, Anhui, and Jiangsu provinces); $I V$, double rice in southern China. Province codes: 1, Heilongjiang; 2, Jilin; 3, Liaoning; 4, Yunnan; 5, Guizhou; 6, Sichuan; 7, Chongqing; 8 , Hubei; 9, Anhui; 10, Jiangsu; 11, Hunan; 12, Jiangxi; 13, Zhejiang; 14, Fujian; 15, Guangdong; 16, Guangxi

The yearly district-, county-, or subprovince-level (usually including five to eight counties) data on rice yields and growing areas were obtained from the statistical yearbook of each county or province. For some $0.5^{\circ} \times 0.5^{\circ}$ grids used for model calibration and validation (Fig. 1), the yearly rice phenology, including planting, flowering, and mature dates, was obtained from the nearest agricultural meteorological stations; yearly growing-area-weighted yields were calculated from district-level data on their growing area and yield. For the study provinces, yearly rice-yield series were obtained from the statistical yearbook of each province. Then, the rice yields (1980-2008) in these grids and provinces were detrended using 5-year moving averages to produce yield data with the management technology in the base year, which were used as observed yields in later analyses.

\subsection{Calibration and validation of the MCWLA-Rice model}

In MCWLA-Rice, there are 20 parameters that are generally related to the processes of crop phenological and leaf area index (LAI) development, light and water use, photosynthesis and transpiration rate, temperature stress, and yield formation; a Bayesian probability inversion and a Markov chain Monte Carlo (MCMC) technique have been applied to MCWLA-Rice for analyzing uncertainties in parameter estimation (Tao and Zhang 2013). Accordingly, the prior 
intervals of these parameters are presented in Table S2 (see Supplementary Materials). On the basis of these efforts, we further generated 10,000 initial parameter sets by Latin hypercube sampling as in Shuai et al. (2015). For each province, it is assumed that across a certain province both the rice cultivar and management practices are similar. The grids marked in red with large cultivated rice areas (Fig. 1) were selected as representative grids for each province. Then the weather, soil, and observed yield data from 1982 to 1994 in the red grids were used for calibration, and those from 1995 to 2006 were used for validation.

In each red grid, we selected the optimal 30 sets of parameters, which produced the minimum root mean-square error (RMSE) between the simulated and observed yield series and meanwhile produced reasonable flowering and maturity dates within a 2-week window from the observations. Next, an ensemble mean yield prediction (YdEn) was derived for each grid by averaging the outputs derived from each set of parameters. For the simulated yields in each province, the yearly growing-area-weighted yields were calculated from the grid-level data on the growing area and simulated yield, assuming that the yearly growing area ratio at each grid did not change throughout the period as in previous studies (Shuai et al. 2015; Tao and Zhang 2013). The performance of MCWLA-Rice was validated by calculating the Pearson correlation coefficient $(r)$ and RMSE between the simulated and observed yield series at grid and province scales. Correlations were considered significant at $p<0.1$.

\subsection{Analysis}

In general, ETS in China can be classified into three major types based on the impact mechanism: delayed cool injury, sterile-type chilling injury, and heat damage. For brevity, we use Table 1 to provide more details about the physiological process, the representative indicator from the model outputs, and some references for each ETS types. For each set of parameters, MCWLA-Rice was first run for each $0.5^{\circ} \times 0.5^{\circ}$ grid with the actual historical climate (1981-2010). In each year, the ensemble mean values of the simulated yield and three ETS indicators were calculated to represent $\mathrm{Y}_{\mathrm{ETS}}, \mathrm{MD}_{\mathrm{ETS}}, \mathrm{SL}_{\mathrm{ETS}}$, and $\mathrm{SH}_{\mathrm{ETS}}$ for each grid, respectively. Likewise, MCWLA-Rice was run again to obtain $\mathrm{Y}_{\text {noETS }}, \mathrm{MD}_{\text {noETS }}, \mathrm{SL}_{\text {noETs }}$, and $\mathrm{SH}_{\text {noETS }}$ in each grid under the similar climate with only the historical extreme temperatures removed according to the following criterion: in the daily simulation during rice vegetative stage, if $\mathrm{T}_{\text {mean }}$ was below $T_{\text {low }}$, it was raised to $T_{\text {low }}$, or if $\mathrm{T}_{\text {mean }}$ was above $T_{\text {high }}$, it was reduced to $T_{\text {high }}$; during rice reproductive stage, if $\mathrm{T}_{\text {mean }}$ was below $T_{\text {low }}$, it was raised to $T_{\text {low }}$, or if $\mathrm{T}_{\max }$ was above $T_{\text {high, }}$ it was reduced to $T_{\text {high. }}$. The extreme-temperature thresholds in different stages of rice development were summarized in Table 2. Here, the ensemble simulations were used to account for the uncertainties from the biophysical processes of the crop model, as well as a wide range of crop cultivars with contrasting phenological and thermal characteristics.

Based on the above estimations, the following indexes could be calculated by:

$$
I_{\mathrm{ETSimp}}=\frac{I_{\mathrm{ETS}}-I_{\mathrm{noETS}}}{I_{\mathrm{ETS}}} \times 100 \%
$$

where $I(\%)$ represents each of Y, MD, SL, and SH; $I_{\text {ETSimp }}$ means the impact of ETS on each indicator; please note that $\mathrm{YL}_{\mathrm{ETS}}$ has the same mean as $Y_{\mathrm{ETSimp}}$.

The ensemble means of $\mathrm{YL}_{\mathrm{ETS}}, \mathrm{MD}_{\mathrm{ETSimp}}, \mathrm{SL}_{\mathrm{ETSimp}}$, and $\mathrm{SH}_{\mathrm{ETSimp}}$ for each grid/year combination were derived by averaging the outputs from the optimal 30 sets of parameters. Then, we calculated the mean and linear trends of 30-year YL $\mathrm{LTS}_{\mathrm{ETS}}$ series (1981-2010), and also their decadal-change type (1980s, 1990s, and 2000s) at a grid scale, to help understand the 
Table 1 Three major types of ETS based on the impact mechanism

\begin{tabular}{|c|c|c|c|}
\hline ETS types & Physiological processes & $\begin{array}{l}\text { Representative indicators } \\
\text { from the model outputs }\end{array}$ & References \\
\hline $\begin{array}{l}\text { Delayed cool } \\
\text { injury }\end{array}$ & $\begin{array}{l}\text { Low temperatures during the } \\
\text { vegetative period, delayed } \\
\text { rice growth, lead to poor } \\
\text { conditions for grain filling } \\
\text { and hence reduce the final } \\
\text { yield }\end{array}$ & $\begin{array}{l}\text { MD: the simulated } \\
\text { maturity date }\end{array}$ & \multirow[t]{3}{*}{$\begin{array}{l}\text { Ma et al. (2009); Sun } \\
\text { and Huang (2011); } \\
\text { Tao et al. (2013); } \\
\text { Tao and Zhang } \\
\text { (2013); Wang } \\
\text { et al. (2014b); } \\
\text { Wang et al. (2009) }\end{array}$} \\
\hline $\begin{array}{l}\text { Sterile-type } \\
\text { chilling injury }\end{array}$ & $\begin{array}{l}\text { Low temperatures during } \\
\text { the booting and } \\
\text { heading-flowering stages } \\
\text { cause floral impotency, } \\
\text { lead to high spikelet } \\
\text { sterility, and hence } \\
\text { reduce the final yield }\end{array}$ & $\begin{array}{l}\text { SL: the percentage of } \\
\text { spikelet sterility due to } \\
\text { low temperatures } \\
(\gamma c \text { in Eq. S3) }\end{array}$ & \\
\hline Heat damage & $\begin{array}{l}\text { High temperatures during } \\
\text { the heading-flowering } \\
\text { stage affect pollen } \\
\text { formation and } \\
\text { development, damage } \\
\text { insermination, lead to } \\
\text { high spikelet sterility, } \\
\text { and hence reduced the } \\
\text { final yield }\end{array}$ & $\begin{array}{l}\text { SH: the spikelet sterility } \\
\text { due to high } \\
\text { temperatures } \\
\text { ( } \gamma h \text { in Eq. S6, } \\
\text { dimensionless) }\end{array}$ & \\
\hline
\end{tabular}

Note: Eq. S3 and Eq. S6 are in Supplementary Materials

spatio-temporal patterns of yield loss due to extreme temperatures across China; furthermore, we investigated the dominant ETS-impacting type by calculating the Pearson correlation coefficients $(r)$ between the 30-year series of $\mathrm{YL}_{\mathrm{ETS}}$ and three indicators from the MCWLARice outputs (i.e., $\mathrm{MD}_{\mathrm{ETSimp}}, \mathrm{SL}_{\mathrm{ETSimp}}$, and $\mathrm{SH}_{\mathrm{ETSimp}}$ ).

\subsection{An overview of the abbreviations in this study}

Given a lot of abbreviations in the text, we list all of them with full names to help keep track of

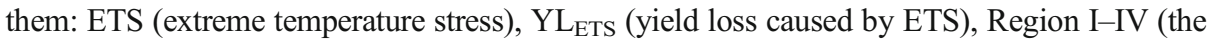
codes of the studied four regions in Fig. 1), P1-16 (the provinces codes in Fig. 1), MD (the

Table 2 Extreme-temperature thresholds in different stages of rice development.

\begin{tabular}{|c|c|c|c|c|c|}
\hline \multirow[t]{2}{*}{ Region } & \multicolumn{2}{|c|}{$\begin{array}{l}\text { Rice vegetative period } \\
\text { (DVI: } 0-0.75 \text { ) }\end{array}$} & \multicolumn{2}{|c|}{$\begin{array}{l}\text { Rice reproductive } \\
\text { period (DVI: } 0.75-2.0 \text { ) }\end{array}$} & \multirow[t]{2}{*}{ References } \\
\hline & $\mathrm{T}_{\text {mean }}\left({ }^{\circ} \mathrm{C}\right) T_{\text {low }}$ & $\mathrm{T}_{\text {mean }}\left({ }^{\circ} \mathrm{C}\right) T_{\text {high }}$ & $\mathrm{T}_{\text {mean }}\left({ }^{\circ} \mathrm{C}\right) T_{\text {low }}$ & $\begin{array}{c}\mathrm{T}_{\max }\left({ }^{\circ} \mathrm{C}\right) \\
T_{\text {high }}\end{array}$ & \\
\hline I & 10 & 30 & 19 & 35 & \multirow{4}{*}{$\begin{array}{l}\text { GB/T 21985-2008 (2008), } \\
\text { QX/T 101-2009 (2009), } \\
\text { Sun and Huang (2011), } \\
\text { Tao et al. (2013), Wang } \\
\text { et al. (2014a), Zhang et al. } \\
\text { (2014) }\end{array}$} \\
\hline II & 10 & 30 & 20 & 35 & \\
\hline III & 10 & 30 & 20 & 35 & \\
\hline IV & 12 & 30 & 22 & 35 & \\
\hline
\end{tabular}


simulated maturity date), SL (the percentage of spikelet sterility due to low temperatures), SH (the spikelet sterility due to high temperatures), $\mathrm{MD} / \mathrm{SL} / \mathrm{SH}_{\mathrm{ETSimp}}$ (the ETS impacts on each indicator), D1-3 and I1-3 (the decadal change types of $\mathrm{YL}_{\mathrm{ETS}}$ defined in Section 3.2).

\section{Results}

\subsection{Model validation at grid and province scales in China}

The mean estimates and standard deviations of the optimal 30 parameter sets in each province are listed in Table S2. The $r$ and RMSE between YdEn and the observed yield series in some crop model grids and all of the provinces were presented in Table 3. Here, the RMSE was presented as a percentage of the average yield to provide a relative measure of accuracy comparable across pixels. At a grid scale, $r$ ranged from 0.07 to 0.51 and RMSE from 9.95 to $15.04 \%$. At a province scale, $r$ ranged from 0.13 to 0.63 and RMSE from 5.41 to $9.73 \%$.

Table 3 The RMSE and $r$ between the modelled (YdEn) and observed yield series at the grid and province scales.

\begin{tabular}{|c|c|c|c|c|c|c|c|}
\hline \multirow[t]{2}{*}{ Region code } & \multirow{2}{*}{$\begin{array}{l}\text { Province code } \\
\text { (grid number) }\end{array}$} & \multicolumn{2}{|c|}{ Purple grid A } & \multicolumn{2}{|c|}{ Purple grid B } & \multicolumn{2}{|c|}{ Province level } \\
\hline & & RMSE(\%) & $r$ & RMSE(\%) & $r$ & $\operatorname{RMSE}(\%)$ & $r$ \\
\hline \multirow[t]{3}{*}{ I } & $\mathrm{P} 1(110)$ & 9.95 & 0.13 & 10.30 & 0.29 & 7.10 & $0.36^{*}$ \\
\hline & $\mathrm{P} 2(58)$ & 10.53 & $0.38^{*}$ & 11.73 & 0.17 & 8.93 & $0.34 *$ \\
\hline & P3 (38) & 12.48 & 0.24 & 12.83 & 0.23 & 7.19 & $0.59 *$ \\
\hline \multirow[t]{2}{*}{ II } & $\mathrm{P} 4$ (109) & 10.65 & $0.35^{*}$ & 10.87 & $0.47 *$ & 7.16 & 0.26 \\
\hline & P5 (59) & 12.59 & 0.19 & 13.99 & $0.46^{*}$ & 8.32 & $0.32 *$ \\
\hline \multirow[t]{4}{*}{ III } & P6 and P7 (114) & 14.91 & $0.46^{*}$ & 11.44 & 0.21 & 7.87 & 0.13 \\
\hline & $\mathrm{P} 8(60)$ & 10.13 & 0.27 & 15.04 & 0.31 & 7.06 & $0.53^{*}$ \\
\hline & P9 (47) & 12.20 & $0.42 *$ & 10.75 & 0.28 & 7.77 & 0.27 \\
\hline & $\mathrm{P} 10(40)$ & 11.46 & 0.18 & 13.96 & $0.39 *$ & 8.64 & $0.33^{*}$ \\
\hline \multirow[t]{6}{*}{ IV_ER } & P11 (73) & 10.98 & 0.12 & 10.39 & 0.25 & 7.96 & $0.53 *$ \\
\hline & $\mathrm{P} 12(61)$ & 14.80 & 0.26 & 12.41 & $0.48^{*}$ & 5.41 & $0.63^{*}$ \\
\hline & P13 (36) & 12.57 & 0.16 & 13.61 & $0.37 *$ & 8.87 & $0.59 *$ \\
\hline & $\mathrm{P} 14$ (43) & 11.52 & $0.37^{*}$ & 14.71 & $0.46^{*}$ & 9.73 & 0.22 \\
\hline & $\mathrm{P} 15(61)$ & 10.23 & $0.47^{*}$ & 12.85 & 0.19 & 7.42 & $0.51^{*}$ \\
\hline & P16 (83) & 13.36 & 0.34 & 10.67 & 0.26 & 6.27 & $0.36^{*}$ \\
\hline \multirow[t]{6}{*}{ IV_LR } & P11 (73) & 12.72 & 0.22 & 13.26 & 0.16 & 7.61 & $0.45^{*}$ \\
\hline & P12 (61) & 13.56 & 0.33 & 11.73 & 0.29 & 6.53 & $0.34^{*}$ \\
\hline & P13 (36) & 15.06 & 0.07 & 12.98 & $0.47^{*}$ & 9.28 & $0.41^{*}$ \\
\hline & P14 (43) & 11.55 & $0.44 *$ & 10.90 & 0.27 & 6.86 & $0.34^{*}$ \\
\hline & $\mathrm{P} 15(61)$ & 10.15 & 0.29 & 14.05 & $0.41 *$ & 8.45 & 0.21 \\
\hline & P16 (83) & 11.80 & 0.18 & 12.78 & 0.26 & 7.17 & $0.42 *$ \\
\hline
\end{tabular}

Here, RMSE is presented as a percentage of the average yield to provide a relative measure of accuracy comparable across pixels. For each province, the purple grid A lies to the south of grid B in Fig. 1. P6 and P7 are considered as a single province because they were not separated until 1997

${ }^{*} p<0.1$ 
Generally, the relative performance of MCWLA-Rice across different areas could be attributed to the heterogeneous features of agricultural cultivation system (e.g., different harvest times and crop rotations) and management practices. The relationships between rice yields and weather over a larger scale were better captured, as the agricultural management practices were generally more homogeneous. Overall, the performances of the MCWLA-Rice model did reach an acceptable level suggested by the previous studies (Tao et al. 2009; Tao and Zhang 2013) and could be used for the further analysis.

\subsection{Spatio-temporal pattern of $\mathrm{YL}_{\mathrm{ETS}}$ at the grid scale in China}

The spatial pattern of the average YLETS (1981-2010) at a grid scale in China is presented in Fig. 2(a). Almost all of the major irrigated rice planting areas have been hit by ETS over the past decades, showing average-YL $\mathrm{YLTS}_{\mathrm{ETS}}$ values ranging from 0.01 to $50 \%$. Heavier losses $(>10 \%)$ were found in most of Regions I and $\mathrm{III}_{2}$, the west of Region $\mathrm{III}_{1}$, the middle of Region II, and some portions of Region IV (Fig. 2(a)). In general, for each province in Regions I, II, and IV_LR, YLETS in the northern areas was more severe than that in the southern areas; however, the pattern was reversed for each province in the other regions with heavier loss occurring in the southern areas.

Figure 2(b) illustrates the temporal trends of $\mathrm{YL}_{\mathrm{ETS}}\left(\%\right.$ year $\left.^{-1}\right)$ from 1981 to 2010 . Only the trends with a statistical significance $(p<0.1)$ are shown here. Significant trends of $Y L_{\text {ETS }}$ were mainly distributed in Region I and northern Region IV_LR, with larger decreasing trends $\left(>0.6 \%\right.$ year $\left.^{-1}\right)$ detected in the northern areas of each province. The decadal-change types are presented in Fig. 2(c) to aid understanding of the historical changes of $\mathrm{YL}_{\mathrm{ETS}}$, especially in the areas showing no significant temporal trends. Areas with a decrease in $\mathrm{YL}_{\mathrm{ETS}}$ over the last decade accounted for $\sim 65 \%$ of the major irrigated rice planting areas. And in these areas, Region I was dominated by a continuous decline over the past three decades (type D2), which is consistent with the decreasing trend in Fig. 2(b1); southwestern China has witnessed a slight increase over 1990s, but a large drop over 2000s (type D1); some scattered areas of eastern China have experienced a large increase over 1990s, but a slight drop over 2000s (type D3). An increase in $\mathrm{YL}_{\mathrm{ETS}}$ in the last decade was mainly found in Regions III and IV_ER, where a large drop occurred over 1990s but a slight increase occurred over 2000s (type I1) in the southeastern portions, a continuous increase (type I2) mainly in the eastern part and some areas in P16 and a slight drop over 1990s but a large increase over 2000s (type I3) in the middle of Region $\mathrm{III}_{1}$ and large portions in $\mathrm{P} 8,11$ and 12.

\section{3 $\mathrm{YL}_{\text {ETS }}$ pattern at the province and district scales in China}

The average $\mathrm{YL}_{\mathrm{ETS}}(1981-2010)$ for all grids at the province and district scales are shown in Fig. 3. Based on the median values of the blue boxes, the patterns at the province scale were as follows: across China, there were five provinces exhibiting larger than $10 \%$ losses, showing 20.9, 14.3, 14.2, 11.3, and 10.6 \% for P1-3 and 8-9, respectively; in Region I, higher latitude P1 have suffered from a yield loss 1.5 times larger than the other two provinces; in Region II, yield loss was much larger in P4 (6.3 \%); in Region III, four provinces, including P6 and P8-10, witnessed yield losses larger than $5 \%$; in Region IV_ER, rice yields in P12 and 15 (4.2 and $7.8 \%$, respectively) were hit more severely than that in the other four provinces; in Region IV_LR, yield losses exceeded $5.5 \%$ in P13 and 16. Marked by the median values of the red boxes, the patterns at a district scale could be presented as follows: yield losses in Region I and III were larger (18.4 and 9.0\%, respectively) than 

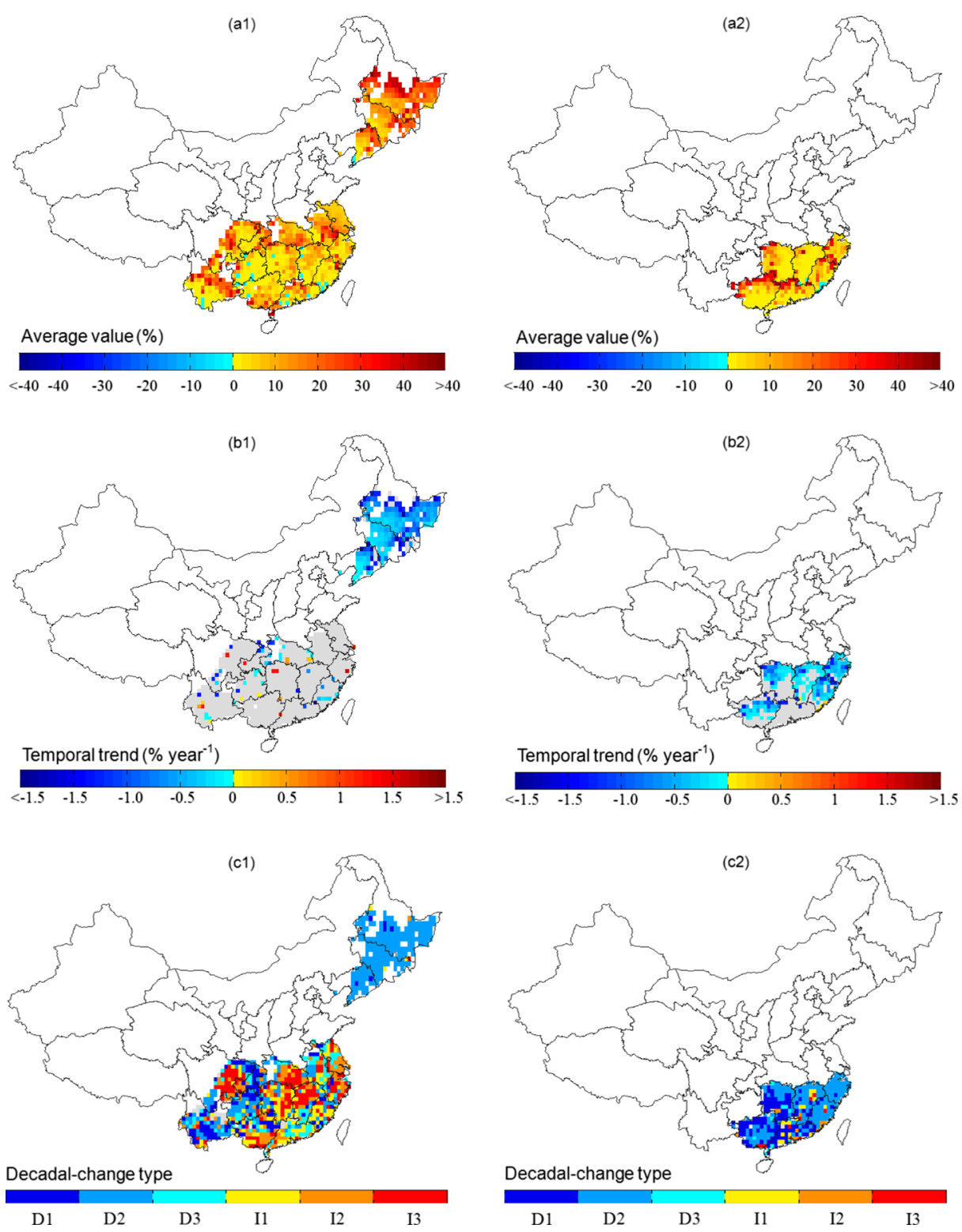

Fig. 2 Spatial distribution of average $\mathrm{YL}_{\mathrm{ETS}}(\%)(a)$, temporal trend $\left(\%\right.$ year $\left.^{-1}\right)(b)$, and decadal-change type of $\mathrm{YL}_{\mathrm{ETS}}(c)$ in China during 1981-2010. $a 1-c 1$ indicate single rice and early rice; $a 2-c 2$ indicate late rice. Only the trends with statistical significance $(p<0.1)$ are shown. The gray areas indicate zero values in $a-b$, and no decadal-change type with at least two decades sharing the same value in $c$. Note: YL $\mathrm{ETS}_{\mathrm{E}}$ of each decade is calculated by averaging 10-year values; the decadal-change type is primarily classified according to the decrease (D1-D3) or increase (I1-I3) in the latest decade (2001-2010). D1, D2, D3, I1, I2, I3 could be illustrated as follows, from left to right:

at the country level (6.1\%); in Region IV, early rice and late rice have suffered similar losses (3.4 and $3.2 \%$, respectively); in contrast, the rice yield loss was smallest (1.4\%) in Region II. 


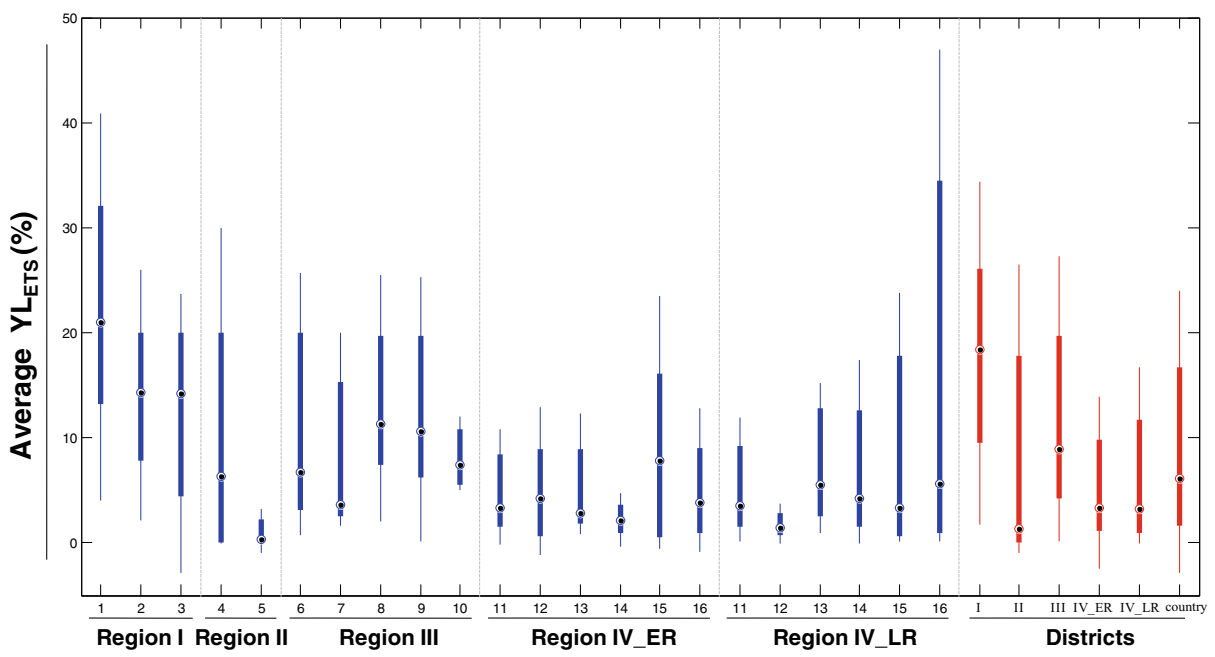

Fig. 3 Box plot of average $\mathrm{YL}_{\mathrm{ETS}}$ (\%) (1981-2010) across the grids at the province and district scales. The numbers in $x$-axis indicate the province codes shown in Fig. 1. The upper and lower hinges of the box indicate the 75th percentile and 25th percentile of the data set, respectively. The black spots inside the boxes indicate median values for the 30 -year analysis period

The temporal patterns of $\mathrm{YL}_{\mathrm{ETS}}$ at province and district scales during 1981-2010 are shown in Table 4. At a province scale, there were seven provinces where more than half of the studied areas had significant downward trends in $\mathrm{YL}_{\mathrm{ETS}}$, and the most rapid decline occurred in P1, 3, and 13_LR (with a median of $-0.62,-0.38$, and $-0.40 \%$ year $^{-1}$, respectively); eight provinces had dominant decadal-change types, including P11_LR and 15_LR showing type D1, P1-3 and P12-14_LR showing type D2. At a district scale, rice cultivation mainly in Regions I and IV_LR exhibited a significant decreasing trend, with a median of -0.53 and $-0.28 \%$ year ${ }^{-1}$, respectively; across China, significant temporal trends of $\mathrm{YL}_{\mathrm{ETS}}$ covered $32.84 \%$ of the study area and the median value was $-0.39 \%$ year $^{-1}$. For decadal changes, only Regions I and IV_LR had a dominant type (D2); in Region II, types D1-2 covered high proportions; in Regions III and IV_ER, the percentage of types I3 (27.30\%) and I1 (26.89\%) ranked highest, respectively; across China, type D2 had the highest proportion (38.25\%).

\subsection{Mechanisms underlying ETS impacts in China}

The temporal patterns of three ETS indicators from MCWLA-Rice outputs are presented in Fig. S1 (please see Supplementary Materials). Overall, $\mathrm{MD}_{\mathrm{ETSimp}}$ had a significant decreasing

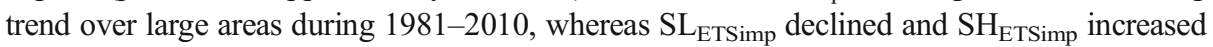
over the latest decade. Figure 4 shows the spatial pattern of the Pearson correlation coefficient ( $r$ ) between the 30-year series of $\mathrm{YL}_{\mathrm{ETS}}$ and the three ETS indicators. These correlations could help identify the ETS-impacting mechanisms in different areas as shown in Table 1.

In most of Regions I and IV_LR and large portions of Region II, both $\mathrm{MD}_{\mathrm{ETSimp}}$ and $\mathrm{SL}_{\text {ETSimp }}$ significantly affected the rice yield losses (Fig. 4(a, b)). Larger correlations for $\mathrm{MD}_{\mathrm{ETSimp}}$ often occurred in the northern areas of these regions (Fig. 4(a)), whereas larger correlations for $\mathrm{SL}_{\mathrm{ETSimp}}$ mainly occurred in southwestern China and southeastern Region IV_LR (Fig. 4(b)). The impacts of $\mathrm{SH}_{\text {ETSimp }}$ were significant in most of Regions III and 


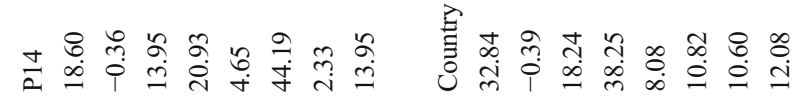

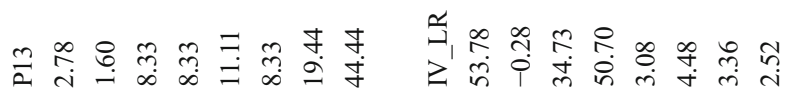

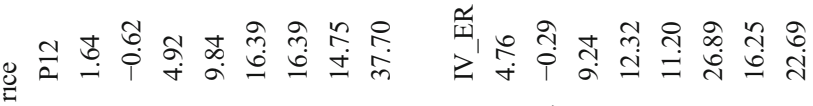

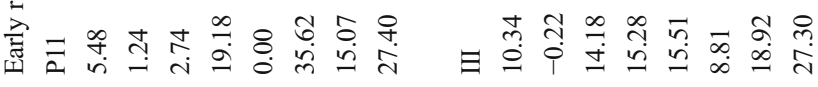

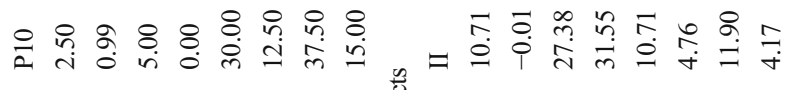

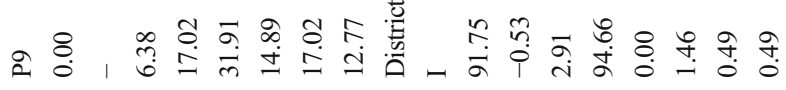

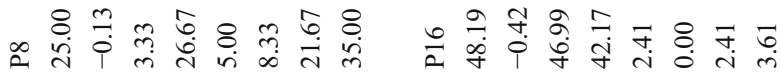

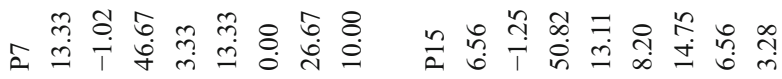
๘ ఓ 士

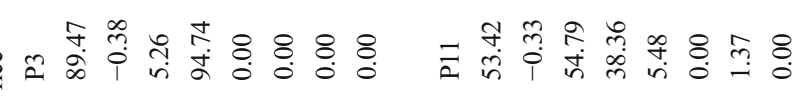
แ क

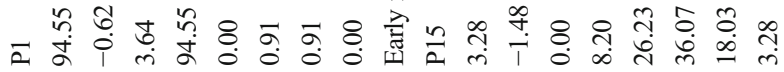

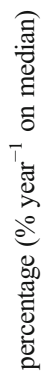

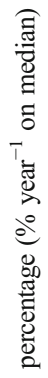
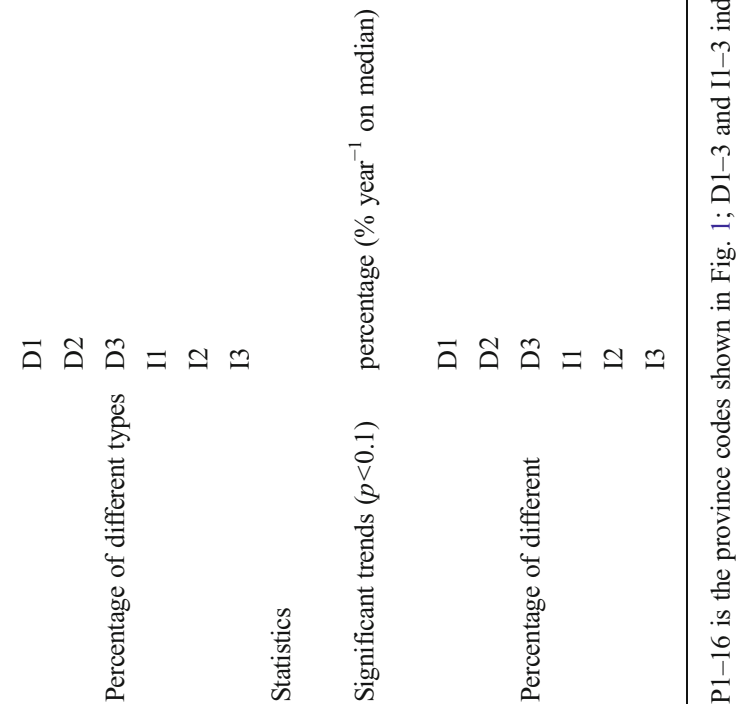

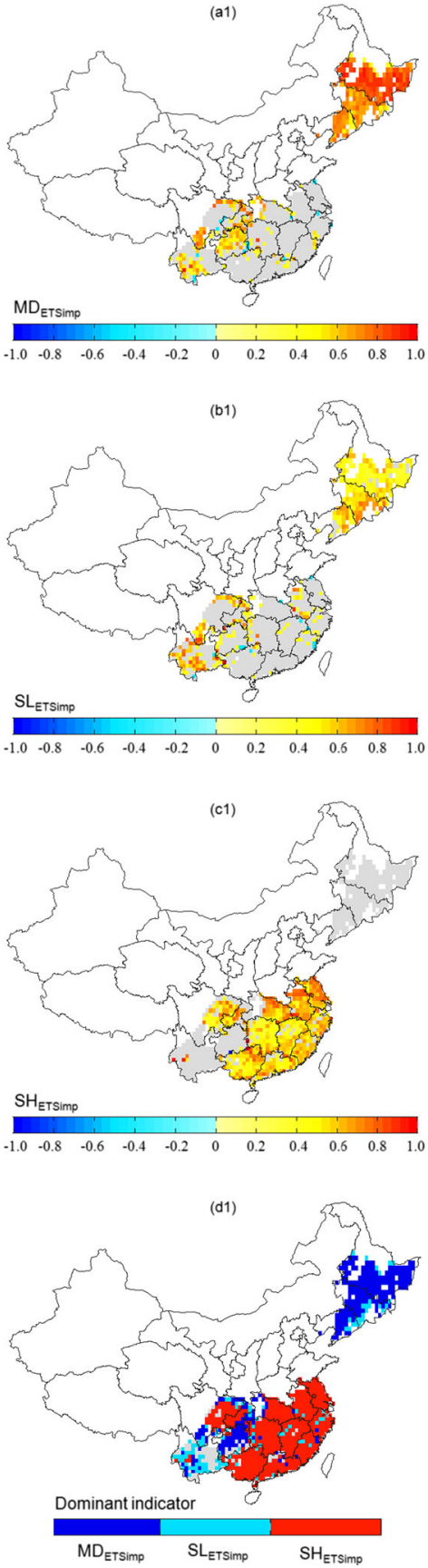
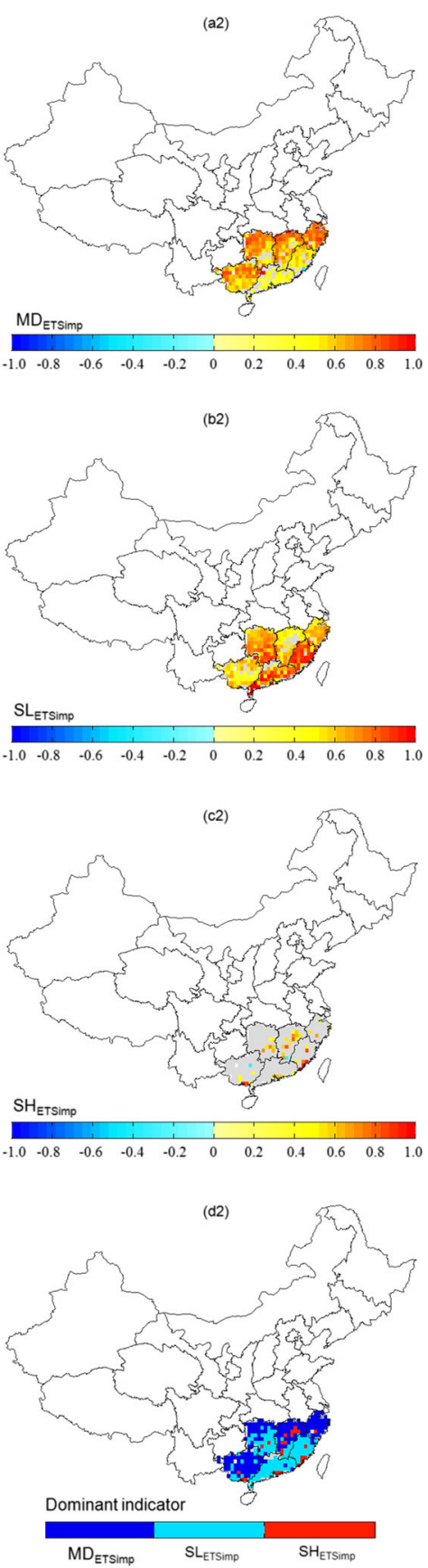

Fig. 4 Spatial patterns of the Pearson correlation coefficient $(r)$ between the data series of $\mathrm{YL}_{\mathrm{ETS}}$ and three key ETS indicators from MCWLA-Rice $(a-c)$ and the dominant types of ETS indicators in China during 1981-2010. $a 1-d 1$ indicate single rice and early rice; $a 2-d 2$ indicate late rice. Only the $r$ with statistical significance $(p<0.1)$ are shown. The gray areas indicate zero values in $a-c$, and no dominant indicator in $c$ 
IV_ER and some scattered areas in the middle of Region IV_LR. In particular, larger correlations were distributed in eastern Region III (Fig. 4(c)). As shown in Fig. 4(d), $\mathrm{MD}_{\text {ETSimp }}$ was the dominant indicator in most of Region I, the northeast of Region II, and northern Region IV_LR; SLETSimp dominated in southwestern Region II and southeastern Region IV_LR; and $\mathrm{SH}_{\mathrm{ETSimp}}$ dominated in most of Regions III and IV_ER.

\section{Discussion}

\subsection{A general view on rice yield loss from ETS and its main mechanism in China}

Based on the process-based crop model MCWLA-Rice and the optimal 30 sets of parameters, the ensemble simulations could help us better understand ETS impacts on rice yield and its main mechanism in China. Over the past decades, rice yields in most of the study area have declined due to ETS, with $\mathrm{YL}_{\mathrm{ETS}}$ ranging from 0.01 to $50 \%$ (Fig. 2). These findings expand on the recent conclusions by Sun and Huang (2011) and Zhang et al. (2014), who only focused on the spatio-temporal pattern of ETS indexes but failed to identify how much yield loss was caused by ETS. In particular, Regions I and $\mathrm{III}_{2}$ were considered to be the most vulnerable areas to ETS (Fig. 3 and Table 4), which is consistent with the findings in many previous studies (Tao et al. 2013; Teixeira et al. 2013; Zhang et al. 2011). Furthermore, concerns should also be given for rice cultivation in some portions of Regions II and $\mathrm{III}_{1}$, the middle of Region IV_ER, and the west and southeast of Region IV_LR, where large YL $\mathrm{ETS}_{\text {ET }}$ values were detected (Fig. 2(a)).

As shown in Table 1, the indicators of the simulated maturity date and the percentage of spikelet sterility due to low temperatures could represent cold stress during different stages, whereas the spikelet sterility due to high temperatures could indicate heat stress during rice sensitive stage. The simulated temporal patterns of these indicators (Fig. S1) substantiated that global warming over the past decades reduced cold stress and increased heat stress on rice production (Tao et al. 2013; Teixeira et al. 2013). Overall, the reduction in cold stress is improving conditions for irrigated rice production across large parts of China. Specifically, the areas affected by cold stress were quite different from those affected by heat stress (Fig. 4), resulting in quite a different temporal pattern of yield loss due to ETS (Fig. 2).

In most of Regions I and IV_LR and large portions of Region II, both delayed cool injury and sterile-type chilling injury significantly affected rice yield (Fig. 4). Under climate warming, the yield losses in these areas declined (Fig. 2) due to the significant decrease in cold stress (Fig. S1). Delayed cool injury was the dominant ETS-impacting type in Region I with poor thermal conditions at high latitudes (Fig. 4(d1)); over the past several decades, rice production here has substantially benefited from the improving temperature conditions (Fig. 2(b1)). Such pattern agreed well with the study of Wang et al. (2014a), who concluded that the improving normal temperature-degree-days contributed much to the increased rice yield in Region I. In the case of reducing cold stress, farmers have been changing their practices to take advantage of new conditions. For instance, under reduced chilling injury conditions in Region I, a series of adaptations (e.g., rapid expansion of rice-planting area and shifts to longer growth-period varieties) have been implemented (Yang et al. 2007).

Consistent with previous analyses (Tao et al. 2013; Zhang et al. 2011), rice cultivations in Regions III and IV_ER were vulnerable to heat stress, as indicated by the significant correlations between $\mathrm{SH}_{\text {ETSimp }}$ and $\mathrm{YL}_{\mathrm{ETS}}$ (Fig. 4). Over recent decades, extreme high-temperature 
events have increased (Zhang et al. 2014), causing an increase in $\mathrm{SH}_{\mathrm{ETSimp}}$ and consequently a substantial increase of $\mathrm{YL}_{\mathrm{ETS}}$ in these areas (Fig. 2). These results expand on the findings based on statistical methods (Wang et al. 2014a), which have only captured the negative contribution of heat-stress increases to rice yields in Region $\mathrm{III}_{1}$. To mitigate the damage from heat stress, farmers could use irrigation to cool both rice plants and the surrounding air or use spray growth regulators (e.g., salicylic acid) to increase the ratio of pollen germination (Shah et al. 2011). Improving heat tolerance of rice cultivars also offers substantial hope for coping with an increasingly hostile environment caused by heat stress.

\subsection{Uncertainties in ETS impact studies}

In this study, based on typical extreme temperature thresholds from previous studies, we ran MCWLA-Rice model to access $\mathrm{YL}_{\mathrm{ETS}}$ of irrigated rice in China. During the analysis, great efforts were made to reduce the uncertainties. For example, we first selected a particular crop model (MCWLA-Rice) in which the impacts of ETS on rice productivity were explicitly parameterized. Furthermore, the ensemble estimations were used to account for the physical and biological uncertainty in the crop model, as well as a wide range of crop cultivars with contrasting phenological and thermal characteristics. A comparison of the simulation results between different studies was important but difficult because few studies assessing past $\mathrm{YL}_{\mathrm{ETS}}$ by crop models could be found. Nevertheless, as stated above, some key results in this study were consistent with the findings from previous studies.

Despite these efforts, some uncertainties in this study were inevitable. The impacts on rice yields due to factors other than weather (e.g., pests and management factors) were modeled in a simplified way by using a single yield-gap parameter as in GLAM (Challinor et al. 2005), which might discount the performances in simulating yield change. When translating temperature-threshold indexes into actual yield losses, more information should be compiled to develop, calibrate, and test yield loss functions that accurately represent the magnitude of yield losses due to extreme temperatures on cereal crops (Rezaei et al. 2015; Siebert et al. 2014). Furthermore, studies with ensembles of crop models should be conducted to improve accuracy and consistency in simulating growth dynamics and ETS impacts (Asseng et al. 2013).

\section{Conclusions}

In this study, by using the MCWLA-Rice model with the ETS impacts explicitly parameterized, we provided a prototype for $\mathrm{YL}_{\mathrm{ETS}}$ assessment to aid understanding of the spatiotemporal patterns of $\mathrm{YL}_{\mathrm{ETS}}$ (1981-2010) and the mechanism underlying ETS impacts in the major irrigated rice planting areas across China. On the basis of optimal 30 sets of parameters, ensemble simulations showed that rice yields in most of the study area have declined due to ETS over the past decades. In particular, Regions I and $\mathrm{III}_{2}$ were considered to be the most vulnerable areas to ETS. Furthermore, large $\mathrm{YL}_{\mathrm{ETS}}$ values were also detected in some portions of Regions II and $\mathrm{III}_{1}$, the middle of Region IV_ER, and the west and southeast of Region IV_LR. Overall, a reduction in cold stress is improving conditions for irrigated rice production across large parts of China. Under climate warming, the temporal patterns of yield loss due to ETS differed across the study area, as indicated by the corresponding ETS-impactingmechanism types. In most of Regions I and IV_LR and large portions of Region II, yield loss declined because the dominant type of cold stress has declined. In most of Regions III and 
IV_ER, yield loss increased because the dominant type of heat stress increased. Nevertheless, due to the uncertainty in translating temperature-threshold indexes into actual yield loss, more accurate yield loss functions and multimodel ensembles should be developed to improve the accuracy of $\mathrm{YL}_{\mathrm{ETS}}$ estimations.

Acknowledgments This study was funded by the National Natural Science Foundation of China (Nos. 41321001; 41571493; 41571088, 31561143003), The Programme of Introducing Talents of Discipline to Universities (B08008).

\section{References}

Asseng S, Ewert F, Rosenzweig C, Jones J, Hatfield J, Ruane A, Boote K, Thorburn P, Rotter R, Cammarano D, Brisson N, Basso B, Martre P, Aggarwal P, Angulo C, Bertuzzi P, Biernath C, Challinor A, Doltra J, Gayler S, Goldberg R, Grant R, Heng L, Hooker J, Hunt L, Ingwersen J, Izaurralde R, Kersebaum K, Muller C, Naresh Kumar S, Nendel C, O/'Leary G, Olesen J, Osborne T, Palosuo T, Priesack E, Ripoche D, Semenov M, Shcherbak I, Steduto P, Stockle C, Stratonovitch P, Streck T, Supit I, Tao F, Travasso M, Waha K, Wallach D, White J, Williams J, Wolf J (2013) Uncertainty in simulating wheat yields under climate change. Nat Clim Chang 3(9):827-832

Bondeau A, Smith PC, Zaehle S, Schaphoff S, Lucht W, Cramer W, Gerten D, Lotze-Campen H, Müller C, Reichstein M, Smith B (2007) Modelling the role of agriculture for the 20th century global terrestrial carbon balance. Glob Chang Biol 13:679-706

Butler EE, Huybers P (2013) Adaptation of US maize to temperature variations. Nat Clim Chang 3:68-72

Challinor AJ, Wheeler TR, Craufurd PQ, Slingo JM, Grimes DIF (2004) Design and optimisation of a large-area process-based model for annual crops. Agric For Meteorol 124(1-2):99-120

Challinor AJ, Wheeler TR, Craufurd PQ, Slingo JM (2005) Simulation of the impact of high temperature stress on annual crop yields. Agric For Meteorol 135(1-4):180-189

Ewert F, Rötter RP, Bindi M, Webber H, Trnka M, Kersebaum KC, Olesen JE, van Ittersum MK, Janssen S, Rivington M, Semenov MA, Wallach D, Porter JR, Stewart D, Verhagen J, Gaiser T, Palosuo T, Tao F, Nendel C, Roggero PP, Bartošová L, Asseng S (2014) Crop modelling for integrated assessment of risk to food production from climate change. Environ Model Softw. doi:10.1016/j.envsoft.2014.12.003

FAO (1991) The digitized soil map of the world (release 1.0). World soil resource Rep. 67. FAO, Rome

GB/T 21985-2008 (2008) Temperature index of high temperature harm for main crops. China Standards Press, Beijing, in Chinese

Haxeltine A, Prentice IC (1996) BIOME3: an equilibrium terrestrial biosphere model based on ecophysiological constraints, resources availability, and competition among plant functional types. Glob Biogeochem Cycles 10:693-709

Horie T, Nakagawa H, Centeno HGS, Kropff M (1995) The rice crop simulation model SIMRIW and its testing. In: Matthews RB et al. (Eds.) Modeling the impact of climate change on rice in Asia. CAB International, Wallingford, UK, pp. 51-66

Iizumi T, Yokozawa M, Nishimori M (2009) Parameter estimation and uncertainty analysis of a large-scale crop model for paddy rice: application of a Bayesian approach. Agric For Meteorol 149:333-348

Lobell DB, Schlenker W, Costa-Roberts J (2011a) Climate trends and global crop production since 1980. Science 333(6042):616-620

Lobell DB, Banziger M, Magorokosho C, Vivek B (2011b) Nonlinear heat effects on African maize as evidenced by historical yield trials. Nat Clim Chang 1(1):42-45

Lobell DB, Sibley A, Ortiz-Monasterio JI (2012) Extreme heat effects on wheat senescence in India. Nat Clim Chang 2(3):186-189

Ma B, Li M, Song J, Wang C (2009) Review on high-temperature stress to rice. Chin J Agrometeorol 31:144 150 (in Chinese)

Moriondo M, Giannakopoulos C, Bindi M (2011) Climate change impact assessment: the role of climate extremes in crop yield simulation. Clim Chang 104(3-4):679-701

Nakagawa H, Horie T, Matsui T (2003) Effects of climate change on rice production and adaptive technologies. In: Mew TW et al. (Eds.) Rice science: innovations and impact for livelihood. International Rice Research Institute. pp. 635-658

QX/T 101-2009 (2009) Grade of chilling damage for rice and maize. Meteorological Press, Beijing (in Chinese) 
Rezaei EE, Webber H, Gaiser T, Naab J, Ewert F (2015) Heat stress in cereals: mechanisms and modelling. Eur J Agron 64:98-113

Seck PA, Diagne A, Mohanty S, Wopereis MC (2012) Crops that feed the world 7: rice. Food Secur 4(1):7-24

Shah F, Huang J, Cui K, Nie L, Shah T, Chen C, Wang K (2011) Impact of high-temperature stress on rice plant and its traits related to tolerance. J Agric Sci 149:545-556

Shuai J, Zhang Z, Tao F, Shi P (2015) How ENSO affects maize yields in China: understanding the impact mechanisms using a process-based crop model. Int J Climatol. doi:10.1002/joc.4360

Siebert S, Ewert F, Rezaei E, Kage R, Graß R (2014) Impact of heat stress on crop yield — on the importance of considering canopy temperature. Environ Res Lett 9(4):044012

Sun W, Huang Y (2011) Global warming over the period 1961-2008 did not increase high-temperature stress but did reduce low-temperature stress in irrigated rice across China. Agric For Meteorol 151(9):1193-1201

Tao F, Zhang Z (2013) Climate change, high-temperature stress, rice productivity, and water use in Eastern China: a new superensemble-based probabilistic projection. J Appl Meteorol Climatol 52:531-551

Tao F, Yokozawa M, Zhang Z (2009) Modelling the impacts of weather and climate variability on crop productivity over a large area: a new process-based model development, optimization, and uncertainties analysis. Agric For Meteorol 149:831-850

Tao F, Zhang Z, Zhang S, Zhu Z, Shi W (2012) Response of crop yields to climate trends since 1980 in China. Clim Res 54:233-247

Tao F, Zhang S, Zhang Z (2013) Changes in rice disasters across China in recent decades and the meteorological and agronomic causes. Reg Environ Chang 13(4):743-759

Teixeira EI, Fischer G, van Velthuizen H, Walter C, Ewert F (2013) Global hot-spots of heat stress on agricultural crops due to climate change. Agric For Meteorol 170:206-215

Wang S, Ma S, Chen L, Wang Q, Huang J (2009) Chilling injury. China Meteorological Press, Beijing (in Chinese)

Wang P, Zhang Z, Song X, Chen Y, Wei X, Shi P, Tao F (2014a) Temperature variations and rice yields in China: historical contributions and future trends. Clim Chang 124:777-789

Wang P, Wei X, Zhang Z, Chen Y, Song X, Shi P, Tao F (2014b) A review of cold injury and heat damage to rice growth under global warming. Resour Sci 36:2316-2326 (in Chinese)

Wheeler T, von Braun J (2013) Climate change impacts on global food security. Science 341:508-513

Yang X, Lin E, Ma S, Ju H, Guo L, Xiong W, Li Y, Xu Y (2007) Adaptation of agriculture to warming in Northeast China. Clim Chang 84(1):45-58

Yuan W, Xu B, Chen Z, Xia J, Xu W, Chen Y, Wu X, Fu Y (2015) Validation of China-wide interpolated daily climate variables from 1960 to 2011. Theor Appl Climatol 119:689-700

Zhang Q, Zhao Y, Wang C (2011) Study on the impact of high temperature damage to rice in the lower and middle reaches of the Yangtze River. J Catastrophol 26:57-62 (in Chinese)

Zhang Z, Wang P, Chen Y, Song X, Wei X, Shi P (2014) Global warming over 1960-2009 did increase heat stress and reduce cold stress in the major rice-planting areas across China. Eur J Agron 59:49-56 